Ruinan, L. (2019). Comparison of Bank Efficiencies between the US and Canada: Evidence Based on

SFA and DEA. Journal of Competitiveness, 11(2), 113-129. https://doi.org/10.7441/joc.2019.02.08

\title{
COMPARISON OF BANK EFFICIENCIES BETWEEN THE US AND CANADA: EVIDENCE BASED ON SFA AND DEA
}

\section{- Ruinan Liu}

\begin{abstract}
This paper aims to achieve two targets. First, using balanced panel data from 2008 to 2017 it compares the cost efficiencies between US and Canadian commercial banks to examine whether structural differences in the two countries' banking industries create differences in efficiencies. Since efficiency is a valuable measurement to indicate the ability of an organization to utilize limited resources to produce, in this article we compare the operating competitiveness of these banks. Next, to achieve the first goal, both the Stochastic Frontier Analysis and Data Envelopment Analysis are employed to examine cost efficiencies in order to find new evidence given the mixed results in previous literature. Profit efficiency is also compared with cost efficiency based on a parametric approach. The results regarding cost and profit efficiency conforms to prior studies indicating a relatively low correlation. However, SFA and DEA produce very different and uncorrelated results, though DEA generates overall lower efficiencies, as expected. Thus, the findings suggest that methodology cross-checking along with information regarding variables selection are necessary before decision making. Essentially, there is not enough evidence to conclude that bank efficiencies are different either between the US and Canada, or between large and small banks in US. However, DEA suggests an increasing trend in average efficiencies, as this parameter is not time-adjusted. A more technical exploration of how to reliably measure efficiencies is awaited to make advancements in this area.
\end{abstract}

Keywords: bank efficiency, Canadian banking, competitiveness, data envelopment analysis, stochastic frontier analysis

JEL Classification: D24, G21

Received: December, 2018

1st Revision: May, 2019

Accepted: May, 2019

\section{INTRODUCTION}

Bank efficiency has become an important topic of research which has produced numerous literature sources concentrating on various aspects of the problem. As the most fundamental compo- 
nent of the financial intermediary, banks perform indispensable roles in accelerating the development of economics by providing credits. A well-developed banking industry is more likely to help maintain the stability of a financial market and avoid banking crises. Measuring efficiency is helpful at both the micro-level and the macro-level, see Berger \& Humphery (1997). On one hand, banks should have a clear understanding of how they are operating by comparing their efficiencies to competitors, and they can adjust their operations accordingly. On the other hand, the government should have a broader picture of how the banking industry is performing, comparing both cross-sectional and through timelines, for early detection of possible dysfunctions in the banking industry and even potential financial crisis induced by inefficient banks.

The literature on efficiency concentrates on widely divergent topics of research, but surprisingly only a few works have compared cost efficiency and profit efficiency, with even fewer of these comparing the two most widely used methods, stochastic frontier analysis and data envelopment analysis, with respect to methodology. See See \& He (2015) for a summary of other methods. Andor \& Hesse (2014) introduced a comparison between SFA, DEA and a new method 'StoNED (stochastic non-smooth envelopment)' proposed by Kuosmanen \& Korelainen (2012). The conclusion is that SFA Maximum likelihood produced the best result, DEA the worst, and StoNED an average result. As for application, most of the literature examines panel data of one country, with some works making comparisons among developing countries and a few mentioning banks in different developed countries. It is worth mentioning that throughout the present paper the author uses the term efficiency to refer to technical efficiency in terms of ease of operation. As a whole, however, economic efficiency is a combination of both technical efficiency and allocative efficiency, with technical efficiency referring to the maximization of output given a fixed level of input, and allocative efficiency allowing adjustment of input to meet consumer preferences. For details of allocative efficiency, see Kumbhakar \& Tsionas (2005) and Ahmad \& Burki (2016) for methods and applications respectively.

The first section of the present study concerns methodology. It not only examines the cost and profit efficiencies of both the US and Canadian banking industries, but also implements stochastic frontier analysis (SFA) data envelopment analysis (DEA). However, the purpose of this study is not to determine which method produces better results, but to demonstrate both approaches for methodology cross-checking and to provide insights for policymakers by using a various range of sources. Consistency of methods will improve the soundness of decision making. The second part of this article deals with the application of the methodology. The panel data includes both the US and Canadian banks from 2008 to 2017, a ten-year period after the 2008 financial crisis, following which details regarding differences in banking structure between the US and Canada are discussed. As for how differences originated and developed, see Mrejen (2013) for details. To the present author's knowledge, this is the first study to compare the differences between Canadian banks and the US banks using these two methods, which use fundamentally different approaches to analyze banking structures.

This study addresses the following questions: Will cost efficiency positively correlate with profit efficiency based on SFA? Do SFA and DEA provide relatively consistent results when implemented in this specific dataset? Is there any difference in bank efficiency between the US and Canada system? 
The rest of the paper is organized as follows: Section 2 discusses literature relevant to the above questions and provides a brief introduction of differences between banks in the US and in Canada. Section 3 explains the methodology of SFA and DEA, as well as introduces the data and model specification. Section 4 provides a discussion of the empirical results with respect to the comparison between methodologies and the two countries. Section 5 presents the conclusions drawn.

\section{THEORETICAL BACKGROUND}

\subsection{Relevant Literature}

With respect to cost and profit efficiency, cost efficiency refers to cost minimization under the constraint of a fixed level of output, while profit efficiency is a broader measurement which allows variations in both costs and revenues. Cost efficiency can be divided into standard profit function and alternative profit function, see Maudos et al. (2002). In some respects, profit efficiency is a more precise approximation of technical efficiency compared to cost efficiency, see Delis et al. (2009). We expect profit efficiency to be lower than cost efficiency due to the former's demonstration of broader flexibility and volatility of profit. Until now, a very limited amount of studies have been conducted comparing these two factors, see Berger \& Mester (1997) and Maudos et al. (2002), with the most recent study Delis et al. (2009), which concludes that the difference between two measurements is not as great as the difference between SFA and DEA.

The second focus of this paper is to compare parametric and nonparametric methods. Among these two categories of methods, stochastic frontier analysis (SFA) and data envelopment analysis (DEA) are the most widely used, respectively. SFA not only produces a parametric function to be used in stage two, but also produces a theoretically more precise estimate of efficiency. The reason for this is that SFA allows a random error to be separated from the inefficiency measurement, which typically follows a truncated normal distribution. However, the disadvantage of SFA is that it maintains an underlying assumption regarding the distribution of the frontier. On the contrary, DEA imposes no prior assumption about the distribution of inefficiency, with one effect of this relative neutrality being that no random error is counted in the measurement of inefficiency. Thus, DEA will theoretically generate higher inefficiencies than SFA. Methodology cross-checking in this way began with Ferrier \& Lovell (1990), which examined US banks using both SFA and DEA. The present paper to some extent replicates the methods of this study. However, prior to the saving and loan crisis in the 1980s, the US banking structure consisted of unit banking, dramatically different from today's branch banking. Thus, a look at data from recent years is necessary. More importantly, we care more about consistency regarding the rankorder of the two methods, which has emerged beginning in the late 1990s as a controversial issue, i.e. Resti (1997), Nguyen (2016) agree regarding consistency, while Ferrier and Lovell (1990), Delis et al. (2009), Dong et al. (2013) reveal relatively large discrepancies.

The last part of the present paper concerns a comparison between the US and Canadian banks. Literature regarding cross-nation comparisons is limited mainly due to structural differences and inconsistency of data. On one hand, in the literature most attention is devoted to emerging markets in transition, their distinctive characteristics such as state-owned versus private-owned 
status, listing versus not listing on stock exchanges, and the frequency of governmental reforms in recent years, e.g. Bonin et al. (2005) examines 11 transitional countries, Sun \& Chang (2011) examines 8 emerging Asian countries, Maghyereha \& Awartani (2011) examines Gulf Cooperation Council countries. On the other hand, developed markets are not that attractive to researchers because of their relatively stable conditions, consistent government policies and homogeneity among banks in terms of ownership structure. To the present author's knowledge, the only recent relevant literature sources are: Svitálková (2014), which compares bank efficiencies between Austria and the Czech Republic, Gavurova et al. (2017a), which compares Czech and Slovak institutions but focuses on different methods. The studies of Košak et al. (2009), Belas et al. (2018) and Gavurova. et al. (2017b) examine bank efficiencies among EU members. However, whether members in EU should be classified by the cross-nation analysis is questionable, given that these banks in some extent are governed by the same entity and the underlying structures are similar. The difference in efficiency stems from individual difference rather than structural difference. As for the comparison between US and Canadian bank efficiency, the only one the author found is Ghaeli (2018) which uses DEA to examine a cross-sectional data consisting of six US banks and five Canadian banks in 2017 and concludes that Canadian banks are less efficient than the US banks.

In summary, past empirical literature generates mixed results when comparing SFA and DEA while there are limited studies about cost and profit efficiency and most studies use cost efficiency as a measurement of technical efficiency. Therefore, this paper will fill in the gap of literature in this area.

\subsection{Background of banking industries in the US and Canada}

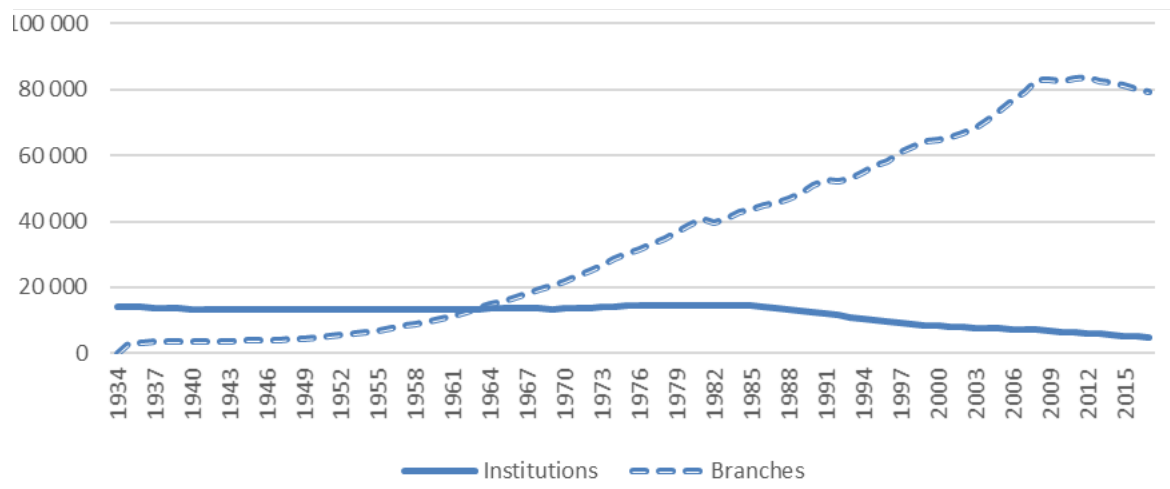

Fig.1 - Number of commercial banks and branches in the U.S. (1934-2017). Source: Federal Deposit Insurance Company (FDIC)

As the motivation and underlying rationale of writing this paper, the structural difference between banking industries in the US and Canada or the uniqueness of the US banks is crucial and should be understood before moving on to following sections. 
Figure 1 shows the number of commercial banks and branches from 1934 to 2017. We can see that the number of institutions remained very high while surprisingly the number of branches was small until the late 20 th century. The reason behind was the domination of the unit-banking structure. At very first, banks were not allowed to open any branch. Then, intrastate branches were allowed while interstate branches were still not available until the saving and loans crisis in the 1980s. 'ATMs are not branches' by the Supreme Court also prompted the development of branching. Not shown in the figure, there were more than 30000 banks in the 1920s but onethird of them failed during the Great Depression. Then people began to realize the benefit of branching. And there was the same logic after saving and loans crisis. Until now, there are still nearly 5,000 banks in the US after a series of major bank failures.

Canada is on the other extreme. In 1868, there were 35 banks, then in 1925, this number reduced to 11 , due to mergers and acquisitions. For now, it has 85 banks and half of them are foreign banks. As for the market share of large banks, 'the big five' in Canada hold $85 \%$ of market shares while the largest five in the US only hold $35 \%$. So, the picture can be described as centralization versus fragmentation. Different regulations in history have made today's differences. And the reason why the author chooses Canada to conduct the research is that Canada is frequently mentioned in history because it shares lots of similarities with the US, however, it experienced zero major banking crises compared to its neighbor. This is the fundamental difference the author believes will also influence the efficiency of banks.

\section{RESEARCH OBJECTIVE, METHODOLOGY AND DATA}

In this section, the author describes two approaches to approximate banks' efficiency: the stochastic frontier analysis using econometrics and the data envelopment analysis using linear programming. SFA will be used to measure both cost efficiency and profit efficiency while DEA will evaluate cost efficiency only.

\subsection{SFA}

Proposed simultaneously by Aigner et al. (1977), Mussuen \& van den Broeck (1977), and first took into the banking sector by Ferrier \& Lovell (1990), the SFA is different from other methods that it separates inefficiencies from random errors. While the random errors usually follow the standard normal distribution, the inefficiency term usually follows a truncated or half normal distribution because inefficiency should be non-negative. The simple format of the SFA model to measure cost efficiency follows:

$$
\mathrm{T} C_{i t}=f\left(P_{i p} Q_{i p} Z_{i t}\right)+\mu_{i t}+v_{i t} \quad i=1, \ldots, I ; \quad t=, \ldots, T
$$

where TC is the observed total cost of bank $i$ at time $t, P$ is a vector of input variables, $Q$ is a vector of output variables and $Z$ refers to control variables or environment variables that directly influence the dependent variable. A random error in traditional approach breaks to $\nu$ and $\mu$ which stands for a random error and the truncated normal distribution respectively. We are interested in $\mu$ here because it measures banks' inefficiencies.

According to mainstream literature, the standard translog cost function is the most frequently used, although some provide evidence of consistency between two formats, see Berger \& Mester 
(1997). The author chooses the translog function here to conform to the mainstream. The model specification is of the following format:

$\ln T C_{i t}=$

$\alpha_{0}+\sum_{k=1}^{3} \beta_{i} \ln \left(P_{i}\right)+\sum_{l=1}^{2} \gamma_{l} \ln \left(Q_{l}\right)+\sum_{m=1}^{2} \delta_{i} \ln \left(Z_{m}\right)+$

$\frac{1}{2} \sum_{k=1}^{3} \sum_{n=1}^{3} \zeta_{k n} \ln \left(P_{k}\right) \ln \left(P_{n}\right)+$

$\frac{1}{2} \sum_{l=1}^{2} \sum_{o=1}^{2} \eta_{l o} \ln \left(Q_{l}\right) \ln \left(Q_{o}\right)+\frac{1}{2} \sum_{m=1}^{2} \sum_{p=1}^{2} \theta_{k n} \ln \left(Z_{m}\right) \ln \left(Z_{p}\right)+$

$\sum_{k=1}^{3} \sum_{l=1}^{2} \iota_{k l} \ln \left(P_{k}\right) \ln \left(Q_{l}\right)+\sum_{k=1}^{3} \sum_{m=1}^{2} \varphi_{k m} \ln \left(P_{k}\right) \ln \left(Z_{m}\right)+$

$\sum_{l=1}^{2} \sum_{m=1}^{2} \psi_{l m} \ln \left(Q_{l}\right) \ln \left(Z_{m}\right)+\mu_{i t}+v_{i t}$

where $\mu \sim N^{+}\left(\mu_{i t}, \sigma_{i t}^{2}\right) \quad v_{i t} \sim N\left(0, \sigma_{v}^{2}\right)$

As the model specification shown above, we have three input variables $(\mathrm{P})$ which are price of labor, price of capital and price of funds, two output variables (Q) which are total loan net of allowances for loss and total deposits, and two fixed variables $(\mathrm{Z})$ which are time and equity. To measure profit efficiency, we substitute the $\ln T C$ above with $\ln (\pi+k+1)$ where $\pi$ refers to the observed net operating income before tax and $\mathrm{k}$ is the absolute value of maximum loss among all observations. Thus, the dependent variable will be positive which is essential to the method. Also, the error term now is $v_{i t}-\mu_{i t}$. This is because profit is to be maximized unlike cost to be minimized.

In order to perform the analysis, linearly homogeneity of input variables and symmetric secondorder parameters are two assumptions needed to be imposed. The use of longitudinal setting by adding time trend variable is justified and explained in Kutlu et al. (2019) and Lai \& Kumbhakar (2018). These assumptions partly explain why some researchers prefer DEA which makes no assumption of the underlying distribution of inefficiency.

\subsection{DEA}

There are two subcategories under the DEA, the CRS and the VRS. While CRS, the original version of DEA proposed by Farrell (1957), assumes a constant return to scales, VRS takes scale efficiency into account. Thus, VRS has been the most widely used approach in this area. Also, there are input-oriented models and output-oriented models. As we are measuring cost efficiency now, we will use the input-oriented DEA-VRS approach to perform the analysis. However, several different DEA-CRS models are also shown to make a comparison.

The DEA-VRS model specification is as follows:

$\theta^{*}=\min _{\lambda, \theta} \theta$, subject to

$\sum_{j=1}^{N} \lambda_{j} X_{i j} \leq \theta X_{i j} \quad i=1,2, \ldots, m$

$$
\sum_{j=1}^{N} \lambda_{j} Y_{r j} \geq Y_{r 0} \quad \mathrm{r}=1,2, \ldots, \mathrm{s}
$$

$\sum_{j=1}^{N} \lambda_{j}=1$

$\theta \geq 0, \lambda_{j} \geq 0 \forall j=1, \ldots, n$

where $n$ is the total number of Decision-Making-Unit (DMU), see Charnes et al. (1978) for the concept of decision-making unit, $i$ is the input while $r$ is the output for a DMU. We can see that 
$\theta^{*}$ is the measurement of efficiency and $\theta^{*}=1$ means the DMU is on the frontier and is the best performing one in the group. The only difference in the model specifications of VRS and CRS is that CRS does not include the last equation. Then, linear programming is used to solve the model from above.

\subsection{Data}

Tab.1 - Variables in the model. Source: author's own

\begin{tabular}{|l|l|l|l|}
\hline & Variables & Notation & Definition \\
\hline \multirow{5}{*}{$\begin{array}{l}\text { Dependent } \\
\text { variables }\end{array}$} & Total cost & TC & $\begin{array}{l}\text { Interest expense + Non-interest } \\
\text { expense }\end{array}$ \\
\cline { 2 - 4 } & Profit & $\pi$ & Net-operating income before tax \\
\hline \multirow{5}{*}{ Input prices } & Price of labor & $\mathrm{P}_{1}$ & $\begin{array}{l}\text { Human resource expense / Total } \\
\text { asset }\end{array}$ \\
\cline { 2 - 4 } & Price of capital & $\mathrm{P}_{2}$ & $\begin{array}{l}\text { Bank premises and fixed expense / } \\
\text { Bank premises and fixed asset }\end{array}$ \\
\cline { 2 - 4 } & Price of funds & $\mathrm{P}_{3}$ & Interest expense / Total deposits \\
\hline \multirow{3}{*}{ Outputs } & Loans & $\mathrm{Q}_{1}$ & Loans net of allowance for losses \\
\cline { 2 - 4 } & Deposit & $\mathrm{Q}_{2}$ & Total deposit \\
\hline \multirow{2}{*}{ Fixed Input } & Equity & $\mathrm{Z}_{1}$ & Equity capital \\
\cline { 2 - 4 } & Time & $\mathrm{Z}_{2}$ & Coded from 1 to 10 \\
\hline
\end{tabular}

Note: The output loan is expressed by total loan - allowance for losses.

The dataset is a balanced panel data consisting of ten largest US banks according to total assets in 2017, ten small banks that are randomly chosen from all national chartered commercial banks according to the list provided by the Federal Deposit Insurance Company (FDIC), and finally five randomly chosen large banks in Canada. For classification, according to FDIC, small banks are those with assets less than $\$ 1.252$ billion for either of the prior two calendar years, effective January 1, 2018. On the contrary, large banks have assets greater than that amount for both prior two calendar years. The time span of the dataset is from 2008 to 2017. This paper only uses National Banks as representatives of all commercial banks because they own the majority of market shares. Also, this classification is the product of history mentioned before, and the charter does not matter in the consumer's perspective and thus ignored in this paper. The data for the US banks were abstracted from the FDIC's database, and the data of Canadian banks were gathered by the author from each bank's annual report. Table 1 summarizes the variables used in the models.

Table 2 below shows the descriptive statistics of variables in the model, and there are two aspects worth mentioning. First, the range of variables is large compared to prior studies mainly due to the intended selection of small banks in the US to compare the influence of bank size on efficiency. Also, the existence of small banks is a unique characteristic in the US which results in the difference mentioned in previous sections. Second, compared to Sun \& Chang (2011), the standard deviation and range of the input variables are surprisingly low. This reflects the stability of input prices in developed countries contrary to emerging countries. 
Tab.2 - Descriptive statistics of variables. Source: author's own calculation

\begin{tabular}{|l|l|l|l|l|}
\hline & Mean & SD & Min & Max \\
\hline Total Cost & 11815.11 & 16642.27 & 1.09 & 64635.00 \\
\hline Profit & 4341.59 & 7494.01 & -16200.00 & 32341.00 \\
\hline \multicolumn{5}{|l|}{} \\
\hline Price of Labor & 0.012611 & 0.005289 & 0.001665 & 0.035855 \\
\hline Price of Capital & 0.733250 & 1.125427 & 0.074440 & 12.21429 \\
\hline Price of Funds & 0.010119 & 0.008011 & 0.000796 & 0.037502 \\
\hline \multicolumn{5}{|l|}{} \\
\hline Loans & 267859.80 & 394266.30 & 41.10 & 1534907.00 \\
\hline Deposits & 182472.00 & 249930.50 & 27.90 & 934264.00 \\
\hline \multicolumn{5}{|l|}{} \\
\hline Equity & 36693.37 & 54734.74 & 6.33 & 211846.00 \\
\hline
\end{tabular}

Note: For monetary variables, unit of measurement is million of US dollars. For Canadian banks, monetary variables are transformed based on currency exchange rate on Oct.31st every year, which is the date of financial reporting in Canada.

\section{RESULTS AND DISCUSSION}

\subsection{Cost efficiency versus profit efficiency}

First, cost efficiency and profit efficiency based on the stochastic frontier are estimated according to the model specification above. Prior literature suggests that profit efficiency is lower than cost efficiency because profit efficiency allows more flexibility in adjusting both input and output while cost efficiency assumes fixed output. Profit efficiency is hard to model due to lack of data of the revenue side, which refers to a different pricing power among banks. In this paper, profit efficiency is only a simple approximation to make a comparison. The analysis of the practical problem is based on cost efficiency which is consistent with literature.

The descriptive results of two efficiencies are shown in Table 3. The mean of cost efficiency is 0.9027 while the profit efficiency is 0.8545 and the standard deviations are 0.0841 and 0.1165 , respectively. They are in line with literature, basically due to the volatility of the income side compared to the cost side. The adjustment to make profit be positive makes this approximation more inaccurate and thus produces an efficiency of 0 . However, unlike Ghaeli (2018) research which removes banks with a negative profit, this paper insists on having these banks. Most other statistics such as Variances, sigma(u), sigma are consistent with expectation. However, the difference between two measurements is not as large as in Delis et al. (2009) and Aysan et al. (2011), probably due to variable selections and specific datasets. 
Tab.3 - Summary of cost and profit efficiency models. Source: author's own calculation

\begin{tabular}{|l|l|l|}
\hline & Cost Efficiency & Profit Efficiency \\
\hline Mean & 0.9027 & 0.8545 \\
\hline SD & 0.0841 & 0.1165 \\
\hline Min & 0.4714 & 0.0000 \\
\hline Max & 0.9884 & 0.9942 \\
\hline N & 250 & 250 \\
\hline Log-Likelihood & 232.9389 & 17.7101 \\
\hline Variances & 0.0105 & 0.0464 \\
\hline$\sigma(v)$ & 0.0396 & 0.0127 \\
\hline$\sigma(\mathrm{u})$ & 0.3030 & 0.6372 \\
\hline$\sigma=\sigma^{2}(\mathrm{u})+\sigma^{2}(\mathrm{v})$ & 0.0934 & 0.4062 \\
\hline Kurtosis & 5.7940 & 12.7550 \\
\hline Skewness & -2.1418 & -2.5293 \\
\hline
\end{tabular}

The practical intention of this research is to figure out the difference between the US and Canadian banks. Table 4 includes results sorted by three groups: large US banks, small US banks and (large) Canadian banks. The results are not as significant as previously expected. On one hand, based on the means of cost efficiency, Canadian banks had the best performances while other groups had similar results, however, the difference is not significant. According to standard deviation, large banks outperformed small banks, especially Canadian banks. This can be explained by the outliers of small banks. On the other hand, profit efficiency provides consistent results except for small US banks, which outperformed large US banks. This study emphasizes the inclusion of small banks for two reasons: 1) numerous small banks within the system is a unique characteristic of US banking, which the author believes is a fundamental difference between the two countries' systems. 2) Past literature intentionally has avoided small banks, not only because they tend to produce unfavorable results, especially in DEA which is highly sensitive to outliers, but also because most emerging markets are structured as large governmentowned banks and foreign banks with nearly no small banks.

Tab. 4 - Cost efficiency and profit efficiency by group based on different methods. Source: author's own calculation

\begin{tabular}{|l|l|l|l|l|l|}
\hline \multicolumn{7}{|l|}{} & Mean & SD & Min & Max & N \\
\hline Cost Efficiency & 0.8995 & 0.0717 & 0.6903 & 0.9866 & 100 \\
\hline US Large & 0.8990 & 0.1048 & 0.4714 & 0.9884 & 100 \\
\hline US Small & 0.9163 & 0.0556 & 0.7845 & 0.9814 & 50 \\
\hline Canadian & 0.8334 & 0.1339 & 0.0000 & 0.9942 & 100 \\
\hline Profit Efficiency & 0.8618 & 0.1080 & 0.4158 & 0.9916 & 100 \\
\hline US Large
\end{tabular}




\begin{tabular}{|l|l|l|l|l|l|}
\hline Canadian & 0.8821 & 0.0863 & 0.6449 & 0.9940 & 50 \\
\hline DEA-VRS & 0.7666 & 0.1739 & 0.3990 & 1.0000 & 100 \\
\hline US Large & 0.6969 & 0.2195 & 0.2246 & 1.0000 & 100 \\
\hline US Small & 0.5419 & 0.1079 & 0.4130 & 0.8742 & 50 \\
\hline Canadian
\end{tabular}

Tab. 5 - SFA results for cost efficiency and profit efficiency. Source: author's own calculation

\begin{tabular}{|c|c|c|}
\hline Variable & SFA-cost efficiency & SFA-profit efficiency \\
\hline$\alpha_{0}$ & $7.574(0.897)$ *** & $3.831(0.958)$ *** \\
\hline Q1 & $3.595(0.517) * * *$ & $-2.023(0.800) *$ \\
\hline Q2 & $-1.794(0.533) * * *$ & $-0.794(0.783)$ \\
\hline P1 & $3.424(0.282) * * *$ & $-2.665(0.610) * * *$ \\
\hline $\mathrm{P} 2$ & $0.547(0.171) * *$ & $1.132(0.553)$ \\
\hline P3 & $0.954(0.258)$ *** & $-1.293(0.639)^{*}$ \\
\hline Z1 & $-0.973(0.455) *$ & $2.385(2.385)^{* *}$ \\
\hline $\mathrm{Z2}$ & $0.336(0.055)$ *** & $0.076(0.131)$ \\
\hline $\mathrm{P} 1^{2}$ & $0.336(0.032) * * *$ & $-0.201(0.081)^{*}$ \\
\hline $\mathrm{P} 2^{2}$ & $0.003(0.011)$ & $0.011(0.025)$ \\
\hline $\mathrm{P} 3{ }^{2}$ & $0.051(0.016) * *$ & $-0.062(-0.044)$ \\
\hline $\mathrm{Q}^{2}{ }^{2}$ & $0.335(0.071)^{* * *}$ & $0.152(0.298)$ \\
\hline $\mathrm{Q}^{2} 2$ & $0.133(0.087)$ & $0.317(0.474)$ \\
\hline $\mathrm{Z1}^{2}$ & $0.166(0.068) *$ & $0.377(0.376)$ \\
\hline $\mathrm{Z}^{2}$ & $-0.000(0.001)$ & $0.002(0.004)$ \\
\hline $\mathrm{P} 1 * \mathrm{P} 2$ & $0.047(0.024)$ & $0.070(0.062)$ \\
\hline $\mathrm{P} 1 * \mathrm{P} 3$ & $0.094(0.034) * *$ & $-0.254(-0.009) * *$ \\
\hline $\mathrm{P} 1 * \mathrm{Q} 1$ & $0.517(0.080)$ *** & $-0.327(-0.197)$ \\
\hline $\mathrm{P} 1 * \mathrm{Q} 2$ & $-0.198(0.088) *$ & $-0.002(0.304)$ \\
\hline $\mathrm{P} 1 * \mathrm{Z} 1$ & $-0.3690(0.066) * * *$ & $0.354(0.261)$ \\
\hline $\mathrm{P} 1 * \mathrm{Z} 2$ & $0.063(0.007) * * *$ & $0.004(0.021)$ \\
\hline $\mathrm{P} 2 * \mathrm{P} 3$ & $0.032(0.016)$ & $0.023(0.049)$ \\
\hline $\mathrm{P} 2 * \mathrm{Q} 1$ & $-0.011(0.059)$ & $0.234(0.182)$ \\
\hline $\mathrm{P} 2 * \mathrm{Q} 2$ & $-0.050(0.072)$ & $-0.093(-0.273)$ \\
\hline $\mathrm{P} 2 * \mathrm{Z} 1$ & $0.056(0.043)$ & $-0.138(0.151)$ \\
\hline $\mathrm{P} 2 * \mathrm{Z} 2$ & $0.006(0.004)$ & $0.006(0.013)$ \\
\hline $\mathrm{P} 3 * \mathrm{Q} 1$ & $0.278(0.047) * * *$ & $0.001(0.125)$ \\
\hline $\mathrm{P} 3 * \mathrm{Q} 2$ & $-0.236(0.057) * * *$ & $-0.156(0.184)$ \\
\hline $\mathrm{P} 3 * \mathrm{Z} 1$ & $-0.041(0.045)$ & $0.128(0.122)$ \\
\hline $\mathrm{P} 3 * \mathrm{Z} 2$ & $0.009(0.007)$ & $-0.004(0.018)$ \\
\hline
\end{tabular}




\begin{tabular}{|l|l|l|}
\hline $\mathrm{Q} 1{ }^{*} \mathrm{Q} 2$ & $-0.311(0.139)^{*}$ & $-0.128(0.728)$ \\
\hline $\mathrm{Q} 1{ }^{*} \mathrm{Z} 1$ & $-0.401(0.081)^{* * *}$ & $-0.154(0.271)$ \\
\hline $\mathrm{Q} 1{ }^{*} \mathrm{Z} 2$ & $0.034(0.013) * *$ & $0.014(0.033)$ \\
\hline $\mathrm{Q} 2{ }^{*} \mathrm{Z} 1$ & $0.079(0.121)$ & $-0.533(0.729)$ \\
\hline $\mathrm{Q} 2{ }^{*} \mathrm{Z} 2$ & $-0.043(0.014) * *$ & $-0.066(0.039)$ \\
\hline $\mathrm{Z} 1{ }^{*} \mathrm{Z} 2$ & $0.007(0.011)$ & $0.049(0.032)$ \\
\hline$\sigma^{\wedge}{ }^{2}$ & 0.093 & 0.406 \\
\hline$\gamma$ & 0.983 & 1.000 \\
\hline$\sigma_{\mathrm{u}}{ }^{2}$ & 0.092 & 0.406 \\
\hline$\sigma_{\mathrm{v}}{ }^{2}$ & 0.002 & 0.000 \\
\hline
\end{tabular}

Note: Statistical significance at the $5 \%, 1 \%, 0.1 \%$ level are indicated by $*, * *, * * *$ respectively. Standard errors are in parentheses. $\sigma_{\mathrm{u}}^{2}=\sigma^{2 *} \gamma\left(\mu \sim \mathrm{N}^{+}\left(\mu, \sigma_{\mathrm{u}}^{2}\right)\right), \sigma_{\mathrm{v}}^{2}=\sigma^{2 *}(1-\gamma)\left(\mu \sim \mathrm{N}\left(0, \sigma_{\mathrm{v}}^{2}\right)\right)$

\subsection{Stochastic frontier analysis versus data envelopment analysis}

Tab. 6 - Descriptive statistics of SFA and DEAs. Source: author's own calculation

\begin{tabular}{|l|l|l|l|l|l|}
\hline & Mean & SD & Min & Max & Median \\
\hline SFA-Cost & 0.9027 & 0.0841 & 0.4714 & 0.9884 & 0.9335 \\
\hline DEA-VRS & 0.6938 & 0.2006 & 0.2246 & 1.0000 & 0.8731 \\
\hline DEA-CRS1 & 0.2236 & 0.2837 & 0.0000 & 1.0000 & 0.1630 \\
\hline DEA-CRS2 & 0.6878 & 0.2071 & 0.2374 & 1.0000 & 0.7034 \\
\hline
\end{tabular}

After the comparison between profit and cost efficiency, we now concentrate on a comparison between SFA and DEA. Table 6 shows descriptive statistics from SFA and DEAs. To explain, DEA-CRS1 is a model with the same specifications as DEA-VRS model, while the DEA-CRS2 model includes equity (Z1) as an input variable for the purpose of evaluating this fixed variable in SFA. The rationale is the following: the only difference is in the economy of scales, see Dong et al. (2014) for details. Thus, if equity is a reliable measurement of bank scale, then the new model should produce similar results compared to the VRS model. The mean comparison ( 0.6878 for CRS2 and 0.6938 for VRS) and the standard deviation (0.2071 for CRS2 and 0.2006 for VRS) confirms this expectation. Thus, equity is indeed a relatively good approximation to scales.

Our main purpose is to compare cost efficiencies measured by SFA and DEA-VRS. We can see from the table that DEA produces both a $23 \%$ lower means (0.6938 vs. 0.9027$)$ and $239 \%$ higher standard deviation ( 0.2006 vs. 0.0841$)$ than the parametric approach. This is consistent with past studies because of the separation of the error term. However, it would be arbitrary to state that SFA produces a better result than DEA, because SFA relies heavily on strong assumptions and predetermined distribution of errors and inefficiencies, as mentioned in section 2. This explains why it is both necessary and beneficial to perform methodology cross-checking. If two approaches converge, then policymakers can have a high level of confidence, otherwise, other insights and development of methods are required. 
Tab. 7 - Spearman's rank order correlation using different approaches. Source: author's own

\begin{tabular}{|l|l|l|l|l|l|}
\hline & SFA-Cost & SFA-Profit & DEA-VRS & DEA-CRS1 & DEA-CRS2 \\
\hline SFA-Cost & 1 & 0.04 & 0.06 & 0.02 & 0.03 \\
\hline SFA-Profit & & 1 & -0.11 & -0.11 & -0.04 \\
\hline DEA-VRS & & & 1 & 0.31 & 0.09 \\
\hline DEA-CRS1 & & & & 1 & $0.69 * *$ \\
\hline DEA-CRS2 & & & & & 1 \\
\hline
\end{tabular}

Note: Statistical significances at the $5 \%, 1 \%, 0.1 \%$ level are indicated by $*, * *, * * *$ respectively.

The result of Table 7 shows the correlation matrix, including all methods performed previously. The result is surprising and inconsistent with the literature. Dong et al. (2014) uses a matrix including SFA, DEA and new DEA (not mentioned in this study) and shows a correlation of around 0.4 which is significant at the $1 \%$ level. However, the matrix above shows roughly no correlation between different approaches at all except a high correlation between DEA-CRS1 and DEA-CRS2 which is definite. Possible explanations include the intrinsic mechanism between SFA and DEA, which would make methodology cross-checking of less value, and the selection of variables and datasets requires further exploration. However, when the same analysis is performed on a truncated dataset with only large banks, the correlation between two approaches is still very low. Thus, we may conclude that although SFA and DEA both attempt to measure cost efficiency, their underlying mechanism forces them to produce very different results.

The last part of Table 4 shows the results of DEA approach, the results of which are the most interesting part of the research. The SFA and the DEA produce exactly the opposite results. DEA-VRS shows the extreme inefficiencies of Canadian banks, 29\% lower than the US large banks, which also outperform small banks by $10 \%$. Though standard deviation of Canadian banks is the lowest, this is an attribute to the low mean and narrow distribution. The highest efficiency is 0.8742 compared to 1 of other groups, which is surprising because this means there is not a single Canadian bank that is both located on the production frontier and minimizing costs. The DEA results are well in line with Ghaeli (2018), which concludes that US banks have higher cost efficiencies than Canadian counterparts. However, this study uses only DEA and thus, an extension of both the methodology and data in this paper question the validity of the conclusion that the US banks outperform Canadian banks.

Tab. 8 - Cost efficiencies of the two methods by time. Source: author's own calculation

\begin{tabular}{|l|l|l|l|l|l|l|l|l|l|l|l|}
\hline & Year & 2008 & 2009 & 2010 & 2011 & 2012 & 2013 & 2014 & 2015 & 2016 & 2017 \\
\hline \multirow{2}{*}{ SFA } & Mean & 0.8712 & 0.9039 & 0.9086 & 0.8995 & 0.8881 & 0.8958 & 0.8974 & 0.9223 & 0.9147 & 0.9253 \\
\cline { 2 - 11 } & SD & 0.1016 & 0.0894 & 0.0914 & 0.0927 & 0.0822 & 0.0955 & 0.1039 & 0.0558 & 0.0576 & 0.0498 \\
\hline
\end{tabular}




\begin{tabular}{|l|l|l|l|l|l|l|l|l|l|l|l|}
\hline \multirow{2}{*}{$\begin{array}{l}\text { DEA- } \\
\text { VRS }\end{array}$} & Mean & 0.5481 & 0.5703 & 0.6193 & 0.6667 & 0.7279 & 0.7342 & 0.7580 & 0.7738 & 0.7800 & 0.7598 \\
\cline { 2 - 10 } & SD & 0.1670 & 0.1659 & 0.1644 & 0.1722 & 0.1871 & 0.1850 & 0.1930 & 0.2075 & 0.1959 & 0.2139 \\
\hline
\end{tabular}

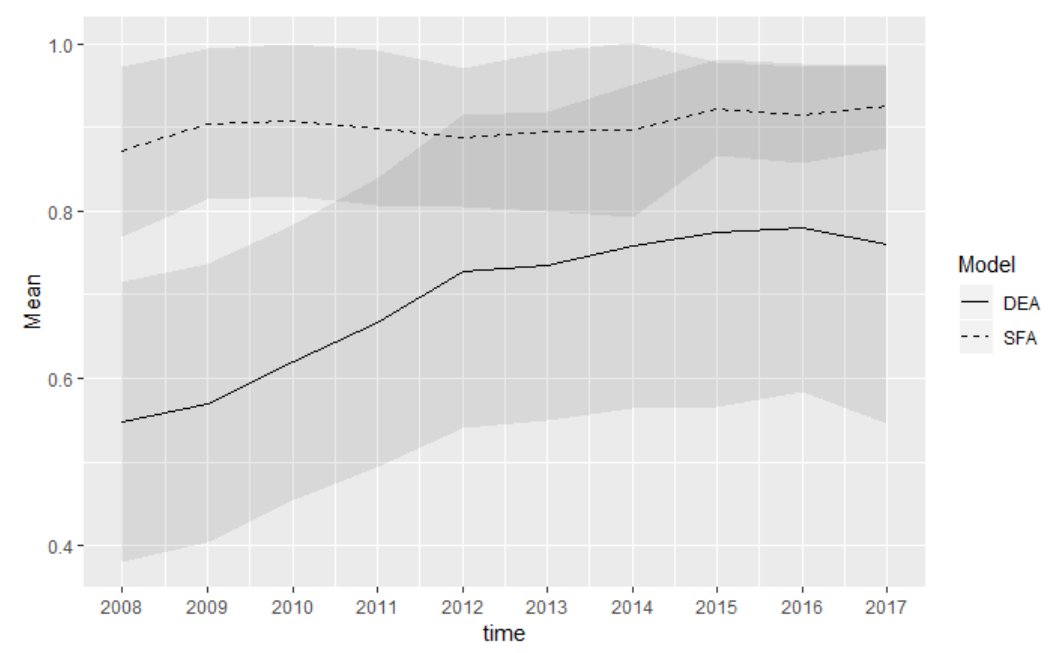

Fig. 2 - Mean and SD of SFA/DEA over time. Source: author's own. Note: Confidence interval is based on one standard deviation for illustration purpose

Instead of making a comparison between groups, we focus now on the time trend based on both methods, a clear representation of which can be seen in Table 8 and Figure 2. For the mean efficiencies, SFA shows a relatively stable mean of around 0.9 from 2008-2017, while DEA-VRS shows a continually increasing mean because DEA analysis is not time-adjusted. For standard deviations, SFA shows a converging trend from 0.1016 in 2008 to 0.0498 in 2017. DEA-VRS indicates a diverging trend from 0.167 in 2008 to 0.2139 in 2017. Thus, the indication of SFA is more convincing, that is, the efficiencies of banks are converging, indicating improvements in the efficiencies of banks previously not well-performing.

\section{CONCLUSIONS}

This paper uses SFA and DEA, two widely used methods in this area, to examine the difference in efficiencies between US banks and Canadian banks to both perform methodology crosschecking as well as conduct an analysis of empirical problem. Few researchers have devoted attention to the Canadian banking industry, which is not only structurally different from the US banking industry, but has also surprisingly experienced no major banking crises, making Canada the only nation to stand out in this regard. This is the first study to detect the efficiency differ- 
ence between these two countries using panel data and extensive methodologies, compared with Ghaeli (2018).

The first section of the research is the comparison between cost and profit efficiency based on SFA. The result shows a slightly higher efficiency and smaller variation measured in cost efficiency, in line with expectation. Then, we move to the methodology cross-checking, which produces inconsistent outcomes. On one side, SFA demonstrates a higher efficiency than does DEA, a result which is unquestionable. On the other side, however, there is a low correlation between SFA and DEA, which proves to controvert the moderate correlation conducted in previous research. This puts decision making on the consistency of methodologies in an unfavorable position. Finally, a time series trend based on two methods is demonstrated. SFA produces a stable mean of efficiency and gradually decreasing variation, while DEA produces an increasing mean and increasing variation.

There are two limitations of the study. First, accounting data are prone to be contaminated due to different accounting standards and the manipulation of management. However, accounting measurement is the best estimate we can obtain to approximate true economic values. Second, variables for SFA and DEA are not the same, as DEA ignores the time effect and performs the analysis as if it is cross-sectional data. Comparing the two methods with different variables may present problems.

In conclusion, some of the results in this paper are consistent with the literature, while others do not agree. The low consistency of SFA and DEA leads to the conclusion that it is better to use different methods and to adjust variables in the same dataset before making decisions given that up to now, no solid research conclusion has come forth regarding variable and method selection. Based on the results of this paper some future research directions are worth exploring: 1) How efficiencies are related to the measurement of accounting profits such as Return on Asset and Return on Equity. This is the problem of whether efficiencies and profits measure the true competitiveness of firms. 2) Given the large number of the US banks, either a study including more data, or a study gathering the data of small banks by state could be helpful to examine the efficiencies on a regional basis. 3) We notice that large changes have been made to the list of national chartered banks due to failure, merger and acquisition. Following this, how would M\&A actions influence the efficiencies of banks? 4) The existence of small banks essentially increase competition. Based on this statement, how would the degree of competition influence efficiency?

\section{References}

1. Ahmad, S., \& Burki, A. A. (2016). Banking deregulation and allocative efficiency in Pakistan. Applied Economics, 48(13), 1182-1196. https://doi.org/10.1080/00036846.2015.109 6001

2. Aigner, D., Lovell, C. A. K., \& Schmidt, P. (1977). Formulation and estimation of stochastic frontier production function models. Journal of Econometrics, 6(1), 21-37. https:// doi.org/10.1016/0304-4076(77)90052-5

3. Andor, M., \& Hesse, F. (2014). The StoNED age: the departure into a new era of efficiency analysis? A monte carlo comparison of StoNED and the "oldies" (SFA and DEA). Journal of 
Productivity Analysis, 41(1), 85-109. https://doi.org/10.1007/s11123-013-0354-y

4. Aysan, A., Karakaya, M., \& Uyanik, M. (2011). Panel stochastic frontier analysis of profitability and efficiency of Turkish banking sector in the post crisis era. Journal of Business Economics and Management, 12(4), 629-654. https://doi.org/10.3846/16111699.2011.599411

5. Belas, J., Gavurova, B., Kocisova, K. \& Delibasic, M. (2018). The Relationship between Asset Diversification and The Efficiency of Banking Sectors in EU Countries. Transformations in Business \& Economics, Vol. 17, No 3C(45C), 479-496

6. Berger, A. N., \& Humphrey, D. B. (1997). Efficiency of financial institutions: International survey and directions for future research. European Journal of Operational Research, 98(2), 175-212. https://doi.org/10.1016/S0377-2217(96)00342-6

7. Berger, A. N., \& Mester, L. J. (1997). Inside the black box: What explains differences in the efficiencies of financial institutions? Journal of Banking \& Finance, 21(7), 895-947. https:// doi.org/10.1016/S0378-4266(97)00010-1

8. Bonin, J. P., Hasan, I., \& Wachtel, P. (2005). Bank performance, efficiency and ownership in transition countries. Banking and the Financial Sector in Transition and Emerging Market Economies, 29(1), 31-53. https://doi.org/10.1016/j.jbankfin.2004.06.015

9. Charnes, A., Cooper, W. W., \& Rhodes, E. (1978). Measuring the efficiency of decision making units. European Journal of Operational Research, 2(6), 429-444. https://doi. org/10.1016/0377-2217(78)90138-8

10. Delis, M. D., Koutsomanoli-Fillipaki, A., Staikouras, C. K., \& Katerina, G. (2009). Evaluating cost and profit efficiency: a comparison of parametric and nonparametric methodologies. Applied Financial Economics, 19(3), 191-202. https://doi.org/10.1080/0960310 0801935370

11. Dong, Y., Hamilton, R., \& Tippett, M. (2014). Cost efficiency of the Chinese banking sector: A comparison of stochastic frontier analysis and data envelopment analysis. Economic Modelling, 36, 298-308. https://doi.org/10.1016/j.econmod.2013.09.042

12. Farrell, M. (1957). The Measurement of Productive Efficiency. Journal of the Royal Statistical Society. Series A (General), 120(3), 253-290. doi:10.2307/2343100

13. Ferrier, G. D., \& Lovell, C. A. K. (1990). Measuring cost efficiency in banking: Econometric and linear programming evidence. Journal of Econometrics, 46(1), 229-245. https://doi.org/10.1016/0304-4076(90)90057-Z

14. Gavurova, B., Belas, J., Kocisova, K., \& Kliestik, T. (2017a). Comparison of selected methods for performance evaluation of Czech and Slovak commercial banks. Journal of Business Economics and Management, 18(5), 852-876. https://doi.org/10.3846/16111699.2017.13 71637

15. Gavurova, B., Belas, J., Kocisova, K., Dapkus, R. \& Bartkute, R. (2017b). Revenue and Cost Efficiency of Banking Sectors in the European Union Countries: Do They Depend on Size, Location or Crisis Period? Transformations in Business \& Economics 16(2), 124-146.

16. Ghaeli M. R. (2018). Measuring the relative efficiency of Canadian versus US banks. Accounting, 5(3), 121-126. https://dx.doi.org/10.5267/j.ac.2018.9.001 
17. Košak, M., Zajc, P., \& Zorić, J. (2009). Bank efficiency differences in the new EU member states. Baltic Journal of Economics, 9(2), 67-89. https://doi.org/10.1080/ 1406099X.2009.10840462

18. Kumbhakar, S. C., \& Wang, H.-J. (2006). Estimation of technical and allocative inefficiency: A primal system approach. Journal of Econometrics, 134(2), 419-440. https://doi. org/10.1016/j.jeconom.2005.07.001

19. Kuosmanen, T., \& Kortelainen, M. (2012). Stochastic non-smooth envelopment of data: semi-parametric frontier estimation subject to shape constraints. Journal of Productivity Analysis, 38(1), 11-28. https://doi.org/10.1007/s11123-010-0201-3

20. Kutlu, L., Tran, K. C., \& Tsionas, M. G. (2019). A time-varying true individual effects model with endogenous regressors. Journal of Econometrics. https://doi.org/10.1016/ j.jeconom.2019.01.014

21. Lai, H., \& Kumbhakar, S. C. (2018). Panel data stochastic frontier model with determinants of persistent and transient inefficiency. European Journal of Operational Research, 271(2), 746-755. https://doi.org/10.1016/j.ejor.2018.04.043

22. Maghyereh, A. I., \& Awartani, B. (2012). Financial integration of GCC banking markets: A non-parametric bootstrap DEA estimation approach. Research in International Business and Finance, 26(2), 181-195. https://doi.org/10.1016/j.ribaf.2011.10.001

23. Maudos, J., Pastor, J. M., Pérez, F., \& Quesada, J. (2002). Cost and profit efficiency in European banks. Journal of International Financial Markets, Institutions and Money, 12(1), 33-58. https://doi.org/10.1016/S1042-4431(01)00051-8

24. Meeusen, W., \& van den Broeck, J. (1977). Technical efficiency and dimension of the firm: Some results on the use of frontier production functions. Empirical Economics, 2(2), 109-122. https://doi.org/10.1007/BF01767476

25. Mrejen, T. (2013). Some Historical Remarks on American and Canadian Banking Reform. The Antitrust Bulletin, 58(4), 651-664. https://doi.org/10.1177/0003603X1305800407

26. Nguyen, T. P. T., Nghiem, S. H., Roca, E., \& Sharma, P. (2016). Bank reforms and efficiency in Vietnamese banks: evidence based on SFA and DEA. Applied Economics, 48(30), 2822-2835. https://doi.org/10.1080/00036846.2015.1130788

27. Resti, A. (1997). Evaluating the cost-efficiency of the Italian banking system: What can be learned from the joint application of parametric and non-parametric techniques. Journal of Banking \& Finance, 21(2), 221-250. https://doi.org/10.1016/S0378-4266(96)00036-2

28. See, K. F., \& He, Y. (2015). Determinants of Technical Efficiency in Chinese Banking: A Double Bootstrap Data Envelopment Analysis Approach. Global Economic Review, 44(3), 286-307. https://doi.org/10.1080/1226508X.2015.1014392

29. Sun, L., \& Chang, T.-P. (2011). A comprehensive analysis of the effects of risk measures on bank efficiency: Evidence from emerging Asian countries. Journal of Banking \& Finance, 35(7), 1727-1735. https://doi.org/10.1016/j.jbankfin.2010.11.017

30. Svitálková Z. (2014). Comparison and Evaluation of Bank Efficiency in Austria and the Czech Republic. Journal of Competitiveness, 6 (2), 15-29 https://doi.org/10.7441/joc.2014.02.02 
Contact information

Ruinan Liu

The University of Chicago

Social Science Division

The United States

E-mail: rliu3@uchicago.edu

ORCID: 0000-0001-7084-2623 